Article

\title{
Potential Use of Dimocarpus longan Seeds as a Flocculant in Landfill Leachate Treatment
}

\author{
Hamidi Abdul Aziz 1,2,*, Nor Aini Rahim ${ }^{1}$ (D), Siti Fatihah Ramli ${ }^{1}$, Motasem Y. D. Alazaiza ${ }^{1}$, \\ Fatehah Mohd Omar ${ }^{1}$ and Yung-Tse Hung ${ }^{3}$ (D) \\ 1 School of Civil Engineering, Engineering Campus, Universiti Sains Malaysia, Nibong Tebal 14300, \\ Penang, Malaysia; aunie78@gmail.com (N.A.R.); ctfatihah88@gmail.com (S.F.R.); \\ my.azaiza@gmail.com (M.Y.D.A.); cefatehah@usm.my (F.M.O.) \\ 2 Solid Waste Management Cluster, Science and Technology Research Centre, Engineering Campus, \\ Universiti Sains Malaysia, Nibong Tebal 14300, Penang, Malaysia \\ 3 Department of Civil and Environmental Engineering, Cleveland State University, \\ Cleveland, OH 44115, USA; yungtsehung@yahoo.com \\ * Correspondence: cehamidi@usm.my; Tel.: +60-4599-6215
}

Received: 19 October 2018; Accepted: 14 November 2018; Published: 16 November 2018

\begin{abstract}
Landfill leachate is a highly polluted and generated from water infiltration through solid waste produced domestically and industrially. In this study, a coagulation-flocculation process using a combination of Polyaluminium chloride ( $\mathrm{PACl}$ ) as a coagulant and Dimocarpus longan seed powder (LSP) as coagulant aid was used in treating landfill leachate. LSP has been tested as the main coagulant and as coagulant aid with $\mathrm{PACl}$. As the main coagulant, the optimum dosage and $\mathrm{pH}$ for $\mathrm{PACl}$ were $5 \mathrm{~g} / \mathrm{L}$ and 6, respectively, with removal efficiencies of $67.44 \%, 99.47 \%$, and $98 \%$ for COD, SS, and color, respectively. For LSP as the main coagulant, results show that LSP is not effective where the removal efficiencies obtained for COD, SS, and color were $39.40 \%, 22.20 \%$, and $28.30 \%$, respectively, with the optimum dosage of $2 \mathrm{~g} / \mathrm{L}$ and $\mathrm{pH} 4$. The maximum removal efficiencies of COD, SS, and color were $69.19 \%, 99.50 \%$, and $98.80 \%$, respectively, when LSP was used as coagulant aid with PACl. Results show that using LSP as coagulant aid was found to be more effective in the removal of COD, SS, and color with less $\mathrm{PACl}$ dosage. The PACl dosage was decreased from 5 to $2.75 \mathrm{~g} / \mathrm{L}$ when LSP was used as a coagulant aid. Cost estimation for using PACl alone and using LSP as the coagulant aid showed a reduction in the cost of approximately $40 \%$ of the cost of using PACl alone. Overall, this study confirmed the efficiency of LSP to be used as a natural coagulant aid in leachate treatment.
\end{abstract}

Keywords: Dimocarpus longan seeds; leachate treatment; coagulant-flocculation; polyaluminium chloride

\section{Introduction}

Landfill is the most widely accepted and prevalent methods for municipal solid waste (MSW) disposal in developing in many countries around the world due to its inherent forte in terms cost saving and simpler operational mechanism [1]. Environmental pollution caused by the landfill leachate has been one of the typical dilemmas of landfilling method [2]. Leachate is the liquid produced when water percolates through solid waste and contains dissolved or suspended materials from various disposed materials and decomposition process. It is often high-strength wastewater with extreme $\mathrm{pH}$, chemical oxygen demand (COD), biochemical oxygen demand (BOD), inorganic salts and toxicity [3,4]. Its composition differs over the time and space within a particular landfill, influenced by a broad spectrum of factors such as waste composition, landfilling practice (solid waste contouring and compacting), local climatic conditions [5], landfill's physicochemical conditions, biogeochemistry and landfill age [6]. 
The composition and characteristics of the landfill leachate are the main factors determine the choices of the treatment method [7].

To protect groundwater aquifer and adjacent surface water from leachate contamination, the handling and treatment of leachate must be meticulously designed to minimize its potential adverse impacts [8]. Biological treatment is an environmentally friendly method that can be applied for the treatment of young or freshly produced leachate [9]. However, it is ineffective for leachate from older landfills that usually contain high COD and ammonium content, low biodegradability (high COD/BOD ratio) and multiple heavy metal ions [10]. In contrast, physical and chemical methods are more effective for older leachate as compared to young leachate [11,12]. Sometimes, the quantity of short-term leachate could be difficult to predict since it mainly depends on precipitation; however, the quantity of long-term can be predicted more accurately [13].

In general, generated leachate at early stages of waste decomposition is highly rich in $\mathrm{BOD}_{5}$ and contains a high amount of biodegradable and nonbiodegradable materials such as volatile fatty acids [12]. However, the stabilized leachate from old landfills is often highly polluted with non-biodegradable organic substances, such as fulvic substances and humic-like, which are measured as COD [14]. Furthermore, the stabilized leachate contains a large quantity of inorganic substances, especially ammonium-nitrogen $\left(\mathrm{NH}_{3}-\mathrm{N}\right)$ [15], which results from the hydrolysis and fermentation of nitrogen-containing fractions of biodegradable refuse substrates. When the bioreactor landfills contain contaminant leachate, collection and in situ recirculation for acceleration of decomposition of readily available organic fractions of wastes, leachate $\mathrm{NH}_{3}-\mathrm{N}$ concentrations may accumulate to produce higher levels as compared to the traditional landfills [16].

Coagulation-flocculation is one of the major chemical methods being used for leachate pretreatment [17]. These methods are applied to remove suspended solids and recalcitrant substances such as humic acid, fulvic acid, or undesirable compounds like heavy metals, absorbable organic halides (AOX) and polychlorinated biphenyls (PCBs) from the leachate [18]. This simple method outshines other advanced technologies like membrane and chemical oxidation technologies in terms of leachate pre-treatment application. The treatment mechanism of this method mainly consists of charge neutralization between negatively charged colloids and cationic hydrolysis products followed by an amalgamation of impurities through flocculation [19]. Total suspended solids (TSS), as well as colloidal particles, are the main parameters removed from this process [20]. The major component of colloid particles is organic compounds. Coagulation is generally defined as destabilization of a colloidal suspension or solution by neutralizing the forces that keep them apart. Cationic coagulants give a positive electric charge that reduces the negative charge of the colloids in solution. As a result, particles of colloid to compose large particles (flocs). Usually, fast mixing is required to disperse the coagulant throughout the solution [21].

The chemistry of coagulation-flocculation is mainly based on the electrical characteristics. The majority of the particles present in the leachate are negatively charged ( -30 to $-40 \mathrm{mV}$ ) [22]. Therefore, they tend to replace each other. Most of the coagulant chemicals are usually used to neutralize the negative charge on colloidal particles to prevent the repelling of these particles with each other [4]. The quantity of coagulant that will be added to the leachate is related to the zeta potential which is known as the electrical potential reflecting the voltage difference between the diffuse layer boundary and the dispersant [23]. Therefore, in the case of large zeta potential, more coagulant is needed. The coagulants have positive charges which attracted to the negative particles in solution; hence the combination of negative and positive charges results in a neutral charge and turn the particles no longer repel each other [4].

The commonly used commercial coagulants are aluminum sulfate (alum), polyaluminum chloride ( $\mathrm{PACl})$, ferrous sulfate, ferric chlorosulphate, and ferric chloride [24]. Inorganic coagulants are generally effective however there are some drawbacks related to the high amount of metal ions in sludge [25] while on the other hand, natural coagulants were found to produce relatively low sludge volume and are safe to humans when compared to the inorganic coagulant [26]. Natural coagulants have 
been widely applied in wastewater treatment [27] but it is still not used widely in landfill leachate treatment despite that they are in abundant quantities, relatively less expensive, and environmentally friendly [28].

In Malaysia, there has been a recent upsurge in the food industry where a large number of solid wastes was generated annually and especially Dimocarpus longan seeds, which are disposed from food manufacturing factories. Dimocarpus longan belongs to Sapindaceae family and goes by many scientific names: Nephelium Dimocarpus longan Camp, Dimocarpus longan Lam, and Euphoria Dimocarpus longan Strand. Currently, Dimocarpus longan is consumed as fresh and processed fruits while the seeds, which account for about $17 \%$ of the fresh weight of whole fruits, are discarded as waste or burned as fuel [29]. The seeds have been found as a rich source of antioxidant phenolic compounds that promising as functional food ingredients or natural preservatives. Soong and Barlow [30] reported that Dimocarpus longan seeds contained high levels of corilagin, gallic acid, and ellagic acid, which have been proven to acquire strong free radical-scavenging activity [31]. The seeds have been shown earlier to contain the hydrolysable tannins (ellagitannins) corilagin and acetonyl-geraniin [32]. Corilagin has been extensively studied for its pharmacological activities in the extract of plants such as Acer nikoense and Phyllanthus amarus and also as a pure isolated compound.

No actual data are available on the production and area of Dimocarpus longan in Malaysia. It is mainly cultivated in Penang and Kedah. Obtaining precise data on the production and acreage of this species is relatively difficult due to its small production. Based on the author's knowledge, there are no published studies in the literature regarding the usage of Dimocarpus longan seed powder (LSP) in wastewater and landfill leachate treatment. The main goal of this study is to investigate the applicability of composite coagulant made from LSP as a natural coagulant in removing color, COD and Suspended Solids (SS) from stabilized leachate. The main objectives of the study are; (i) to determine the optimum $\mathrm{pH}$ and dosage of polyaluminum chloride (PACl) and LSP as the main coagulant in removing COD, SS and color; and (ii) to determine the efficiency of LSP as coagulant aid and PACl as the main coagulant in removing COD, SS, and color.

\section{Materials and Methods}

\subsection{Leachate Sampling and Characterization}

Landfill leachate samples were collected from Alor Pongsu Landfill Site (APLS) in Bagan Serai, Perak, Malaysia from January through April 2018. APLS is classified as an anaerobic stabilized landfill. APLS started its operation in the year of 2000. Since its operation started, the landfill received approximately an average of 660,000 metric tons of solid waste per year, which is roughly 200 metric tons per day [33]. The site covers an area of 10 acres of palm oil plantation. Sampling was carried out using the grab sampling method while preservation was done according to Standard Methods for the Examination of Water and Wastewater [34]. The initial characteristics of the six leachate samples obtained were as contained in Table 1. All samples were kept in HDPE (high-density polyethylene) containers with sealed caps. Samples were transported to the laboratory within $1 \mathrm{~h}$ and stored in a cold room at $4{ }^{\circ} \mathrm{C}$ to minimize biological and chemical reactions prior to any treatability study. Before experiments, leachate samples were conditioned by putting them at room temperature for $2-3 \mathrm{~h}$ and homogenized by manual agitation. During the study, the leachate samples were characterized before and after each treatment. The samples were characterized in terms of turbidity, $\mathrm{pH}$, suspended solids (SS), color, COD, manganese $\left(\mathrm{Mn}^{2+}\right)$, copper $\left(\mathrm{Cu}^{2+}\right)$, iron $\left(\mathrm{Fe}^{3+}\right)$, zinc $\left(\mathrm{Zn}^{2+}\right)$, phosphate $\left(\mathrm{PO}_{4}{ }^{3-}\right)$ and ammonia-nitrogen $\left(\mathrm{NH}_{3}-\mathrm{N}\right)$. All the analytical procedures were performed according to the Standard Method of Water and Wastewater [34]. $\mathrm{pH}$ was measured using a portable $\mathrm{pH}$ meter (CyberScan pH 510, Eutech, Singapore). Turbidity was measured using a turbidimeter (HACH $2100 \mathrm{~N}, \mathrm{HACH}$, Singapore). COD was measured using colorimetric method (5220-D). Heavy metals, $\mathrm{NH}_{3}-\mathrm{N}$, and color were measured using a spectrophotometer (DR/2800, HACH, Singapore). 
Table 1. Characteristics of raw leachate.

\begin{tabular}{cccccc}
\hline Parameter & Min & Max & Average & Std. Dev. & Standard \\
\hline $\mathrm{pH}$ & 7.89 & 8.72 & 8.28 & 0.22 & $6.0-9.0$ \\
Residual conductivity $(\mu \mathrm{S} / \mathrm{cm})$ & 814.00 & 966.00 & 880.94 & 51.19 & - \\
Particle size, d $(\mu \mathrm{m})$ & 0.45 & 94.66 & 61.15 & 23.36 & - \\
COD $(\mathrm{mg} / \mathrm{L})$ & 3016.67 & 3055.00 & 3036.82 & 14.34 & 400 \\
BOD $(\mathrm{mg} / \mathrm{L})$ & \multicolumn{1}{c}{$107.33-176$} & 130.92 & 48.55 & 20 \\
Turbidity $(\mathrm{NTU})$ & 228.75 & 337.50 & 306.25 & 34.59 & - \\
Suspended solids $(\mathrm{mg} / \mathrm{L})$ & 591.67 & 866.67 & 745.00 & 99.67 & 50 \\
Manganese $(\mathrm{mg} / \mathrm{L})$ & 4.17 & 7.50 & 5.83 & 1.49 & 0.2 \\
Iron $(\mathrm{mg} / \mathrm{L})$ & 4.00 & 4.92 & 4.47 & 0.35 & 5.0 \\
Copper $(\mathrm{mg} / \mathrm{L})$ & 3.00 & 5.08 & 4.00 & 0.61 & 0.2 \\
Zinc $(\mathrm{mg} / \mathrm{L})$ & 0.83 & 1.75 & 1.15 & 0.26 & 2.0 \\
Ammonia-nitrogen $(\mathrm{mg} / \mathrm{L})$ & 737.50 & 875.00 & 794.00 & 47.82 & 5.0 \\
Phosphate $(\mathrm{mg} / \mathrm{L})$ & 43.75 & 62.50 & 53.25 & 6.28 & - \\
Color $(\mathrm{PtCO})$ & 4525.00 & 7150.00 & 5517.50 & 794.75 & 100 ADMI \\
\hline
\end{tabular}

\subsection{Preparation of Dimocarpus Longan Seed Powder (LSP)}

The extraction method was adapted from Katayon et al. [35] with some modification by heating distilled water for $30 \mathrm{~min}$ with $100{ }^{\circ} \mathrm{C}$ using a hot plate and stirrer. Firstly, $500 \mathrm{~g}$ of fresh Dimocarpus longan seeds were peeled and separated from its aril. Then, they were washed using tap water to remove dirt before being air-dried for $48 \mathrm{~h}$. After that, the layer, which is called the seeds coat covering the seeds, was removed. The seeds were again air-dried for another $48 \mathrm{~h}$ to ensure that it was completely dry before turning into powder form. The dried seeds were ground using a ring mill for $15 \mathrm{~s}$ until it became a fine powder. Finally, the seed powder was kept in a dry place to be used for experiments to be carried out later.

\subsection{Coagulation-Flocculation}

The current study investigated the coagulation-flocculation process using a combination of $\mathrm{PACl}$ as coagulant and LSP as a coagulant aid. A hydrolyed solution of PACl with the formula of [Al $(\mathrm{OH}) \mathrm{x}$ Cly] (where $\mathrm{x}$ is in the range 1.35-1.65, and $\mathrm{y}=3-\mathrm{x}$ ) and $\mathrm{pH} 2.3-2.9$ due to the presence of hydrochloric acid was supplied by Hasrat Bestari Sdn Bhd, Penang, Malaysia. An 18\% solution of $\mathrm{PACl}$ was used as a stock solution throughout the experiments. Coagulation-flocculation experiments were carried out using jar test apparatus (SW6 Stuart Bibby Scientific Limited, Staffordshire, UK). Leachate samples were allowed to reach room temperature (approximately $3 \mathrm{~h}$ ) before testing, and they were also thoroughly agitated to resuspend any settled solids. The leachate sample volume per beaker was $500 \mathrm{~mL}$. The time and speed for rapid and slow mixing were set with an automatic controller. The jar test consisted of three subsequent stages: (1) rapid mixing stage with speed of $120 \mathrm{rpm}$ for $3 \mathrm{~min}$, (2) slow mixing stage with speed of $20 \mathrm{rpm}$ for $15 \mathrm{~min}$, and (3) final settling time for $45 \mathrm{~min}$. During rapid mixing, the coagulant was added into the beakers while the impellers were maintained at fast speed. After a certain rapid mixing period, the stirrers were set to a slower speed for another period of time. After that, the stirrers were stopped, and the samples were left for final settling. Then, the samples were withdrawn using plastic syringe from $10 \mathrm{~cm}$ below the surface for the analytical determinations. Analyses were undertaken in triplicates. A $500 \mathrm{~mL}$ of leachate samples were filled into six beakers and agitated simultaneously while varying the rotational speed and allowing simulation of different mixing intensities and resulting flocculation process [36].

A preliminary coagulant performance study using jar test was conducted to determine optimum $\mathrm{pH}$ and dosage for $\mathrm{PACl}$ and LSP. It was noteworthy that the preliminary optimum $\mathrm{pH}$ studies were performed first with controlled coagulant dosages and the results were carried over to the preliminary optimum dosage studies as controlled $\mathrm{pH}$ since the $\mathrm{pH}$ would have a major impact on coagulant dosage. Different dosages and $\mathrm{pH}$ were investigated in this study for $\mathrm{PACl}$ and LSP as coagulant aid 
for removing COD, color, and TSS. The examination of $\mathrm{pH}$ effect was performed by adjusting the $\mathrm{pH}$ value of leachate samples between 5 and 9 using solutions of $0.1 \mathrm{~N}$ sulphuric acid $\left(\mathrm{H}_{2} \mathrm{SO}_{4}\right)$ and $0.1 \mathrm{~N}$ sodium hydroxide $(\mathrm{NaOH})$. The removal efficiency was investigated by using LSP as coagulant aid and $\mathrm{PACl}$. Zeta potential test was conducted to enhance the results of the jar test and justify the removal mechanisms of the coagulation process. Zeta potential can present a measure of the net surface charge on the particle and potential distribution at the interface. Consequently, zeta potential serves as an important parameter in the description of the electrostatic interaction between particles in dispersed systems and the properties of the dispersion as affected by this electrical phenomenon [37]. In this study, the surface charge was evaluated by using Malvern Zetasizer Nano ZS. Measurements were taken at $25^{\circ} \mathrm{C}$ with distilled water as the dispersal medium.

\section{Results and Discussion}

\subsection{Characteristics of Leachate}

The physicochemical parameters of landfill leachate are listed in Table 1. The leachate is categorized as stabilized leachate since its $\mathrm{BOD}_{5} / \mathrm{COD}$ ratio $<0.1$. The $\mathrm{BOD}_{5} / \mathrm{COD}$ ratio indicates the degree of biodegradation and landfill age. For example, young leachate has $\mathrm{BOD}_{5} / \mathrm{COD}$ ratio up to 0.83 during the acidogenic phase and decrease to 0.05 for old landfills during methanogenic phase [38]. The low $\mathrm{BOD}_{5}$ and $\mathrm{BOD}_{5} / \mathrm{COD}$ values for stabilized leachate agreed with the literature $[11,15]$. The high concentration of SS (745 mg/L) indicated the presence of organic and inorganic solids. A considerable concentration of ammonia nitrogen was found which is attributed to the decomposition of nitrogenous substances in refuse and the release of soluble nitrogen from solid wastes [15]. The dissolved organics mainly contributed a greater concentration of color (5517 Pt-Co). These organic compounds may be present in the form of recalcitrant material mainly composed of humic-like substances. A low value of $\mathrm{BOD}_{5}$ means low biodegradability while the presence of high concentration of $\mathrm{NH}_{3}-\mathrm{N}$ indicates high leachate toxicity [39].

\subsection{Characteristics of LSP}

Figure 1 illustrates the particle size distribution of LSP using Mastersizer analysis (Malvern Panalytical Ltd., Westborough, MA, USA). Results show that $\mathrm{d}_{10}, \mathrm{~d}_{50}$, and $\mathrm{d}_{90}$ were recorded at $5.317 \mu \mathrm{m}, 13.087 \mu \mathrm{m}$, and $32.460 \mu \mathrm{m}$, respectively. Fourier transformed infrared spectroscopy (FTIR) was used to investigate the structure of LSP and the analysis of their functional groups as shown in Figure 2. The FTIR spectrums of LSP show a weak intensity at $3435 \mathrm{~cm}^{-1}$, due to the O-H stretching and also overlap with a primary amine and aliphatic primary amine due to $\mathrm{N}-\mathrm{H}$ stretching. At $2989 \mathrm{~cm}^{-1}$ the functional group is under carboxylic acid which is bonded by strong $\mathrm{O}-\mathrm{H}$ stretching. This band also overlaps with medium $\mathrm{C}-\mathrm{H}$ stretching under a functional group of an alkane. Under wavenumber $2591 \mathrm{~cm}^{-1}$, Aldehyde with a medium bond of $\mathrm{C}-\mathrm{H}$, ariel together with Thiol is weak in the intensity of S-H stretching. A weak aromatic compound with C-H bonding was found in $1867 \mathrm{~cm}^{-1}$. Alkene shows at $1639 \mathrm{~cm}^{-1}$, with strong and medium bond due to $C=C$ stretching. At $1526 \mathrm{~cm}^{-1}$ the functional group is under nitro compound which is bonded with strong N-O stretching while at $1276 \mathrm{~cm}^{-1}$ there is a strong intensity due to the stretching of C-F bond under fluor compound function. At $1136 \mathrm{~cm}^{-1}$ wavenumber, there is a strong intensity in stretching of sulfone with a strong bond of $S=O$. At wavenumber of $1020 \mathrm{~cm}^{-1}$, strong intensity of $\mathrm{C}=\mathrm{O}$ under a functional group of alkyl aryl-ether, medium intensity of $\mathrm{C}-\mathrm{N}$ stretching with a functional group of amine and also a strong intensity of $\mathrm{C}-\mathrm{O}$ with vibration group on stretching and vinyl ether functional group. Surface morphology for LSP was investigated using a scanning electron microscope (SEM) with different magnifications as shown in Figure 3. They grouped the oval granular of LSP together and formed into a clod of an elliptical. It also had a cloudy or velvety like coating surface. SEM shows that the surface texture of the LSP was rough and there was an accumulation of fine particles with irregular geometric shapes spotted on the surface. 


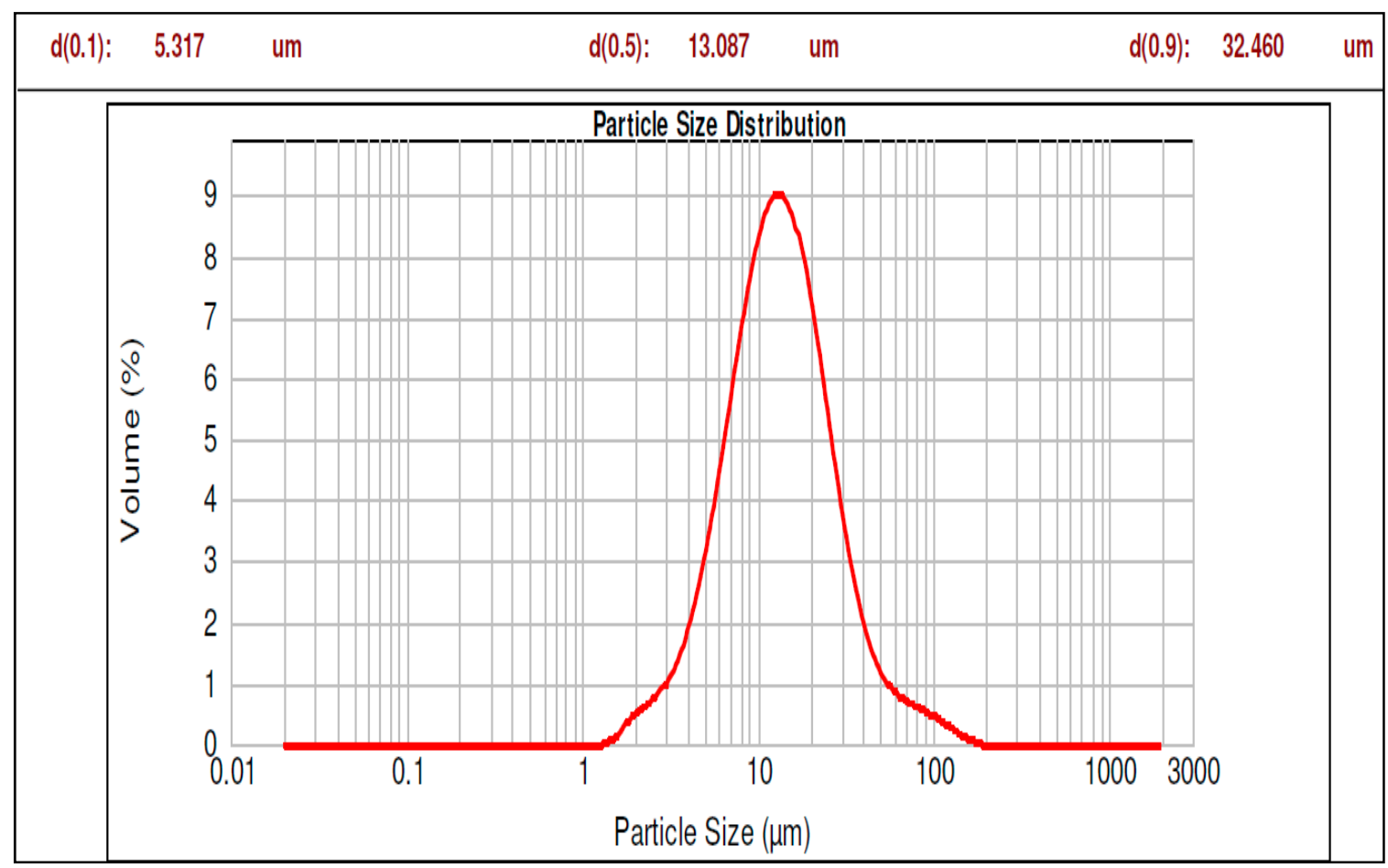

Figure 1. Particle size distribution of LSP (Longan seeds powder).

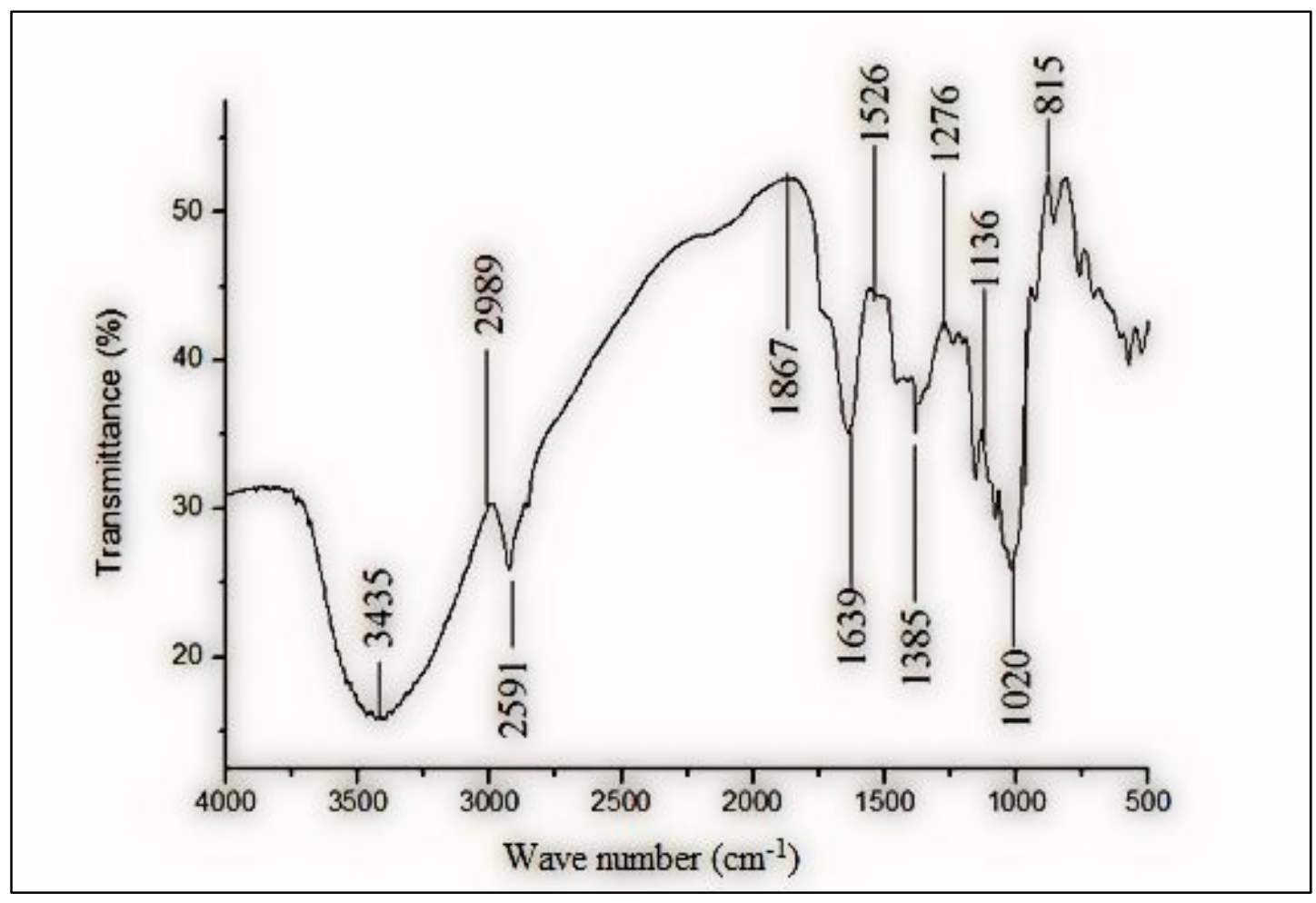

Figure 2. Fourier-transform infrared (FTIR) analysis of LSP. 


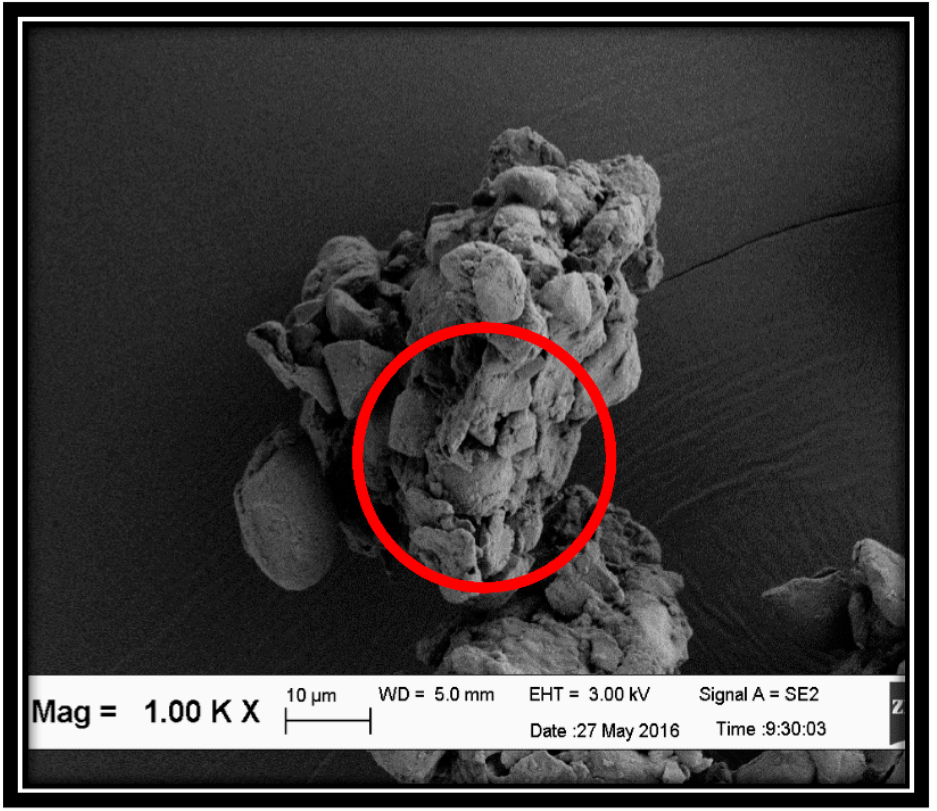

(a)

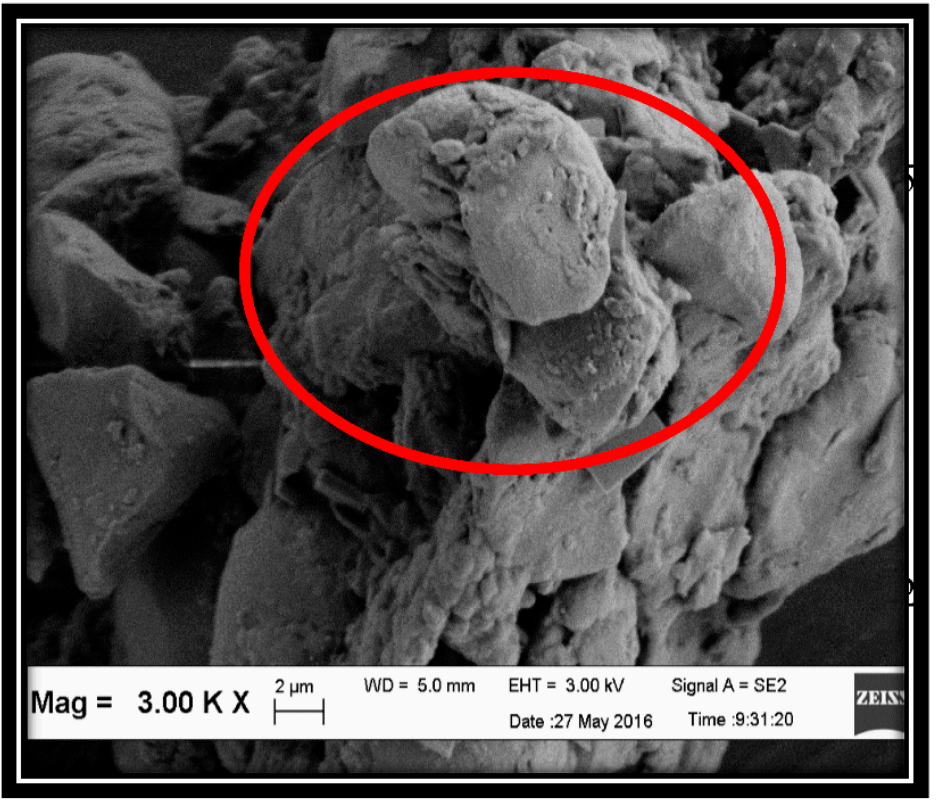

(b)

Figure 3. SEM images of LSP at (a) 1000 magnification (b) 3000 magnification.

\subsection{Determination of Zeta Potential and Particle Size od LSP as a Function of $p H$}

Figure 4 illustrates the zeta potential of LSP in conjunction with $\mathrm{pH}$. It had a negative charge over the same $\mathrm{pH}$ range and reached the point of zero charges (PZC) at $\mathrm{pH} 7$.

LSP has a negative level at surface starting from $\mathrm{pH} 2$ to $\mathrm{pH} 6$. However, at $\mathrm{pH} 7$, the surface charges for LSP had become absolutely neutral and gradually turn negative when it was at $\mathrm{pH} 12$. Under this condition, it could be said that the LSP was anionic coagulants, and the main mechanism governing the aggregation of the constituent was bridging [40]. Figure 5 illustrates the zeta potential and $\mathrm{z}$-average particle size variation in conjunction with $\mathrm{pH}$. It had a negative charge over the same $\mathrm{pH}$ range and reached $\mathrm{PZC}$ at $\mathrm{pH} 7$. 


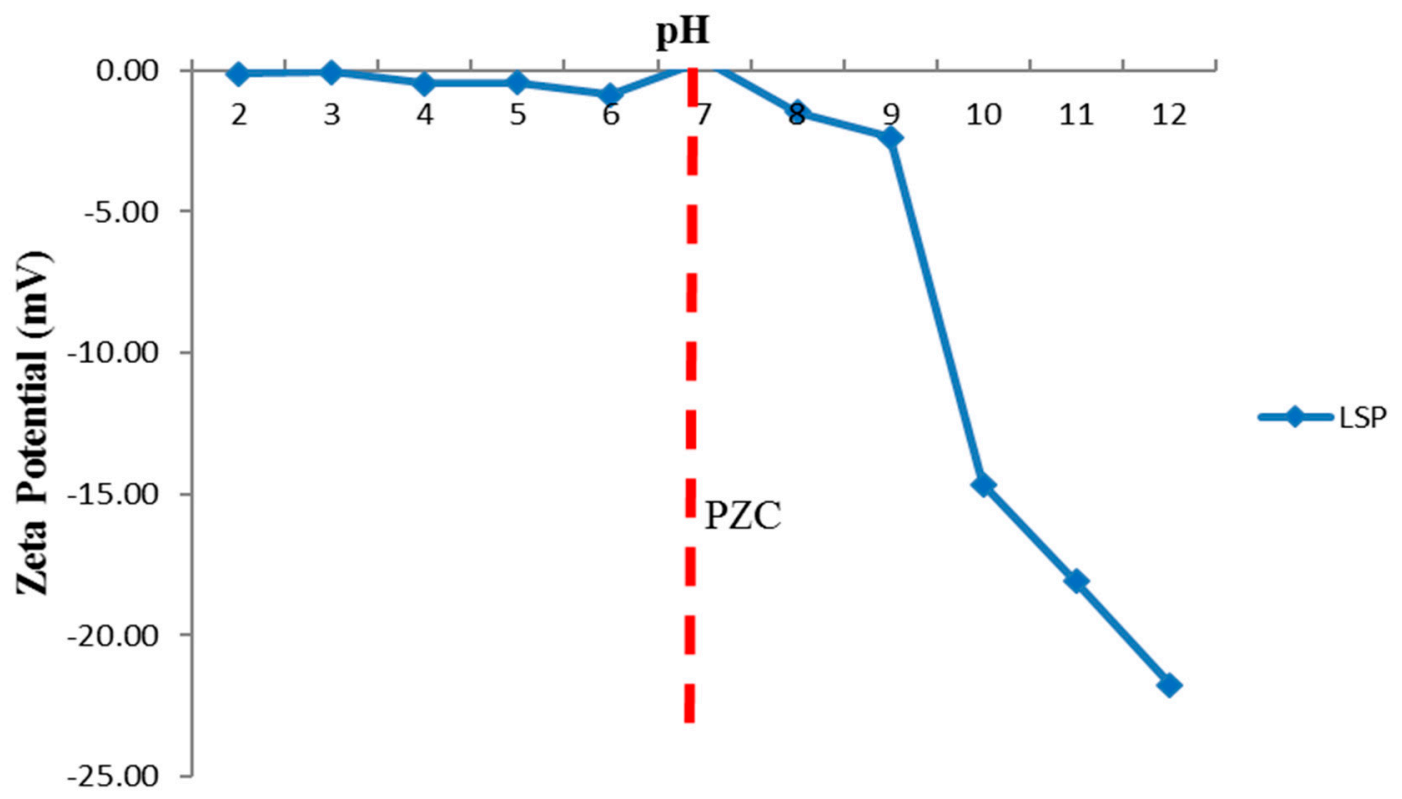

Figure 4. Effect of $\mathrm{pH}$ on the zeta potential values of LSP.

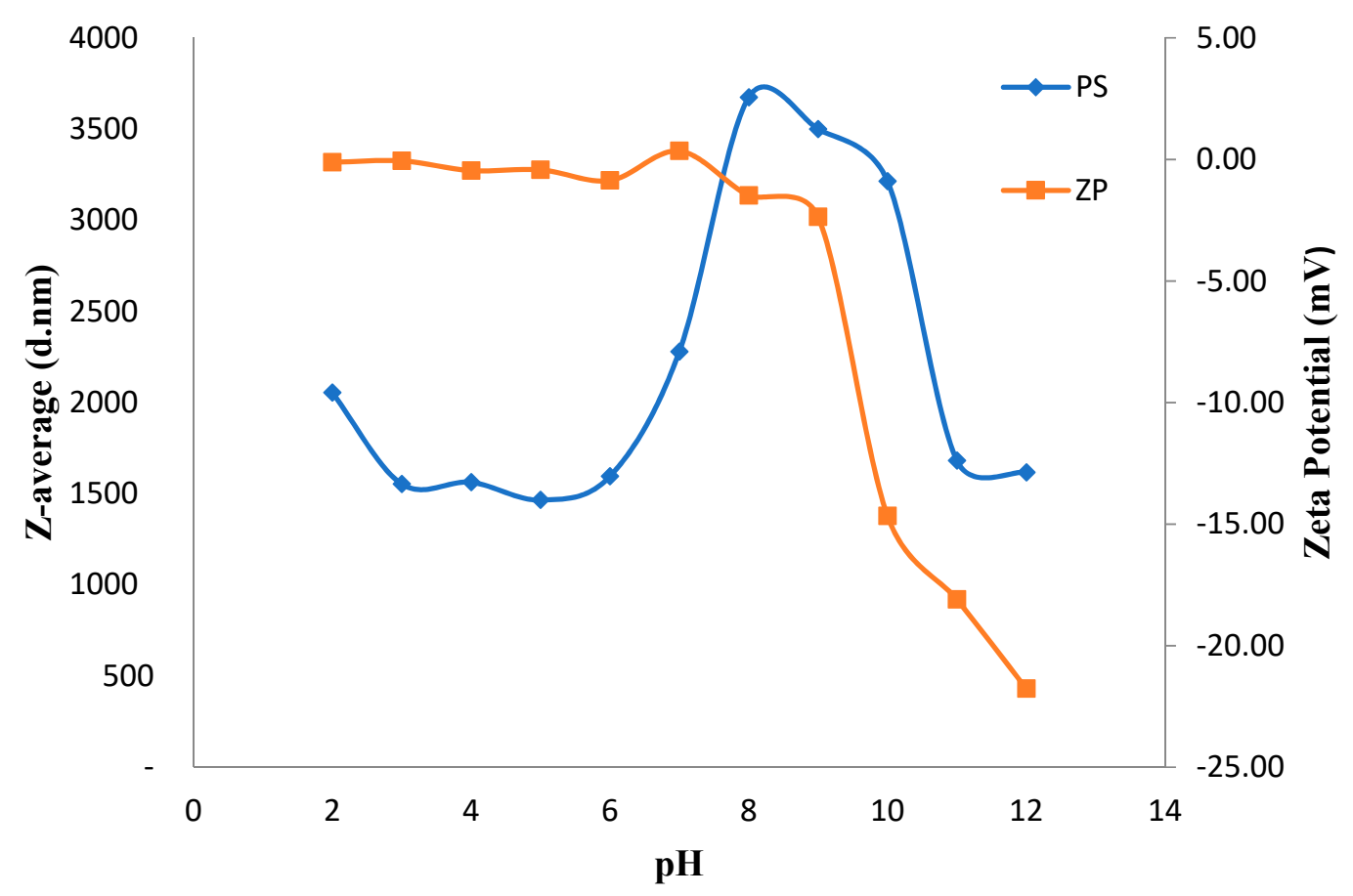

Figure 5. Zeta potential and z-average particle size variation with different $\mathrm{pH}$ values (PS is the particle size, $\mathrm{ZP}$ is the zeta potential).

\subsection{PACl as a Main Coagulant (Optimum $\mathrm{pH}$ and Dosage)}

The preliminary coagulant performance study for $\mathrm{PACl}$ showed that the $\mathrm{PACl}$ is very effective as a main coagulant at $\mathrm{pH} 6$ (data not shown). Therefore, the process of the determination of the optimum dosage for $\mathrm{PACl}$ was conducted by adjusting the $\mathrm{pH}$ value to $\mathrm{pH}$ 6. Figure 6 shows the major range of $\mathrm{PACl}$ dose to remove pollutants at a constant value of $\mathrm{pH} 6$. 


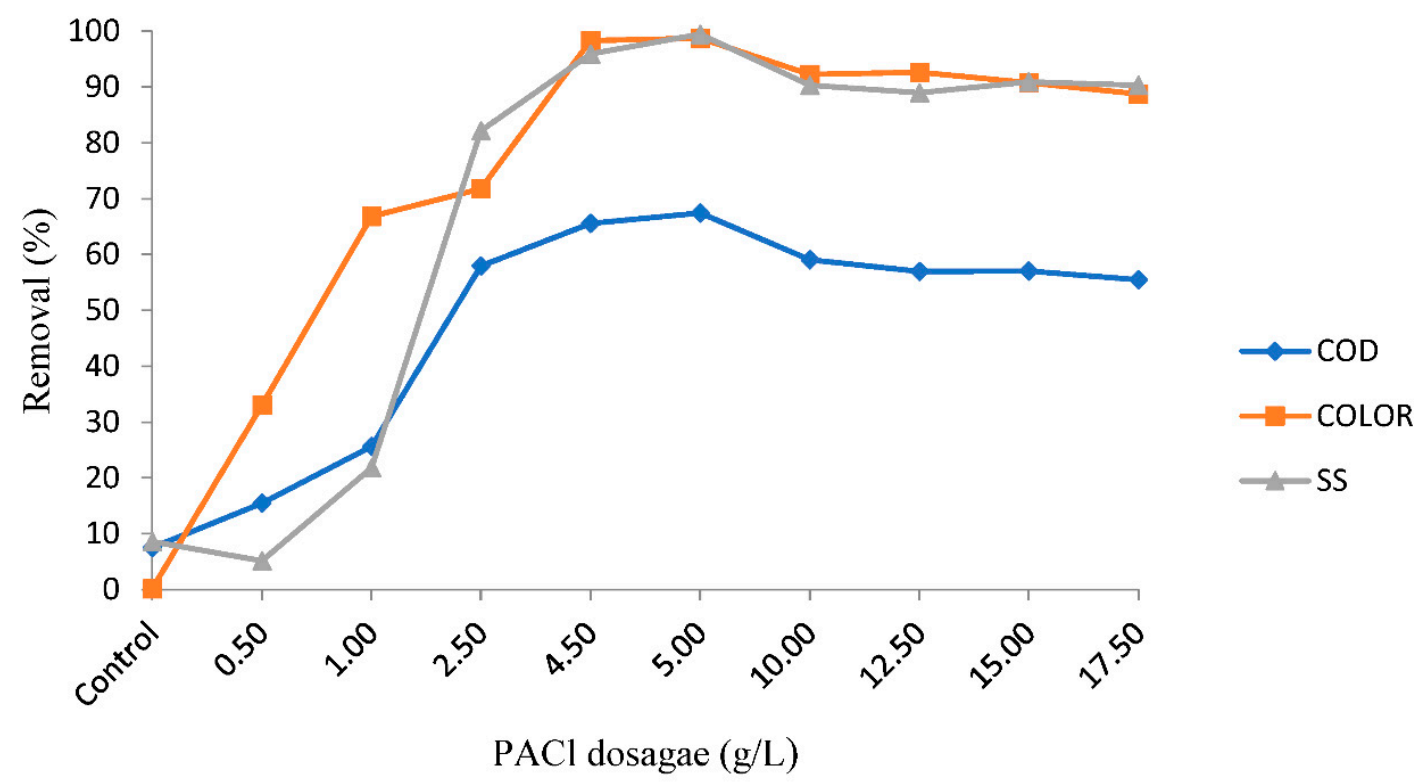

Figure 6. The effect of $\mathrm{PACl}$ in major range of dosage on the removal of COD, color and SS at $\mathrm{pH} 6$.

The observations in Figure 6 show that the highest pollutant removal by $\mathrm{PACl}$ was in the range of $4.25-7.5 \mathrm{~g} / \mathrm{L} \mathrm{PACl}$ dosage. By taking this range as a reference, further coagulation tests on removal was conducted within this major range to get the optimum coagulant dose for PACl. The dosages varied from 4.25 to $7.5 \mathrm{~g} / \mathrm{L}$ at a constant $\mathrm{pH}$ 6. Figure 7 shows the effect of $\mathrm{PACl}$ major range of dosage on the removal of COD, color, and SS at a constant $\mathrm{pH} 6$. Based on the results, the optimum dosage of $\mathrm{PACl}$ was $5.0 \mathrm{~g} / \mathrm{L}$ which achieved highest removal efficiencies of $67.44 \%, 98.73 \%$, and $99.47 \%$ for COD, color, and SS, respectively.

The usage of PACl provided a better removal of color and SS. At the beginning of the experiments, leachate samples have an initial black color due to the presence of a humic substance [41]. The most effective removal of color occurs at the dosage of $5.0 \mathrm{~g} / \mathrm{L}$ with $98.73 \%$. The removal efficiency decreased gradually even though $\mathrm{PACl}$ dosage still added. This observation is most likely because when a large amount of coagulant dosage has been added over the optimum dosage, the surface of the particle's charge reversed due to of continuous absorption of mono and polynuclear hydrolysis species of PACl. The colloidal particles cannot be removed by perikinetic flocculation as they became positively charged particles [42]. The charge neutralization theory can explain this behavior. When a coagulant is added to the landfill leachate at optimum $\mathrm{pH}$, colloid destabilization occurred when positively charged metal ions encounter with negatively charged colloids neutralizes the charge. The removal of particles will only take place more effectively when the more metal-based coagulant is added, as explained by the Schulze-Hardy rule [43]. As a result, when an extra dosage is added, colloids start to absorb the excessive positive charges which remain in the solution and become positively charged. Therefore, the electrical repulsions between positively charged colloids and metal ions occur. The colloids become stable again as the result, weaken the ability of coagulant to remove contaminants. According to Baghvand et al. [44], overdosing of coagulant will disturb the development process. Thus, the right amount of dose should be added to any wastewater treatment.

COD removal for PACl recorded a high removal of $67.44 \%$ at $5.0 \mathrm{~g} / \mathrm{L}$ of PACl. This is because at a higher concentration of coagulant dosage, the flocs produced have a good consistency and in a better structure than at a lower dosage [45]. Below the optimum dosage, the removal of COD by PACl is not effective due to the fact that at lower concentrations of dose, a smaller floc is produced, and it influenced the velocity of the sludge [46]. SS also has the same pattern of removal, where the highest removal of SS was $99.47 \%$ at $5.0 \mathrm{~g} / \mathrm{L}$ of PACl. 


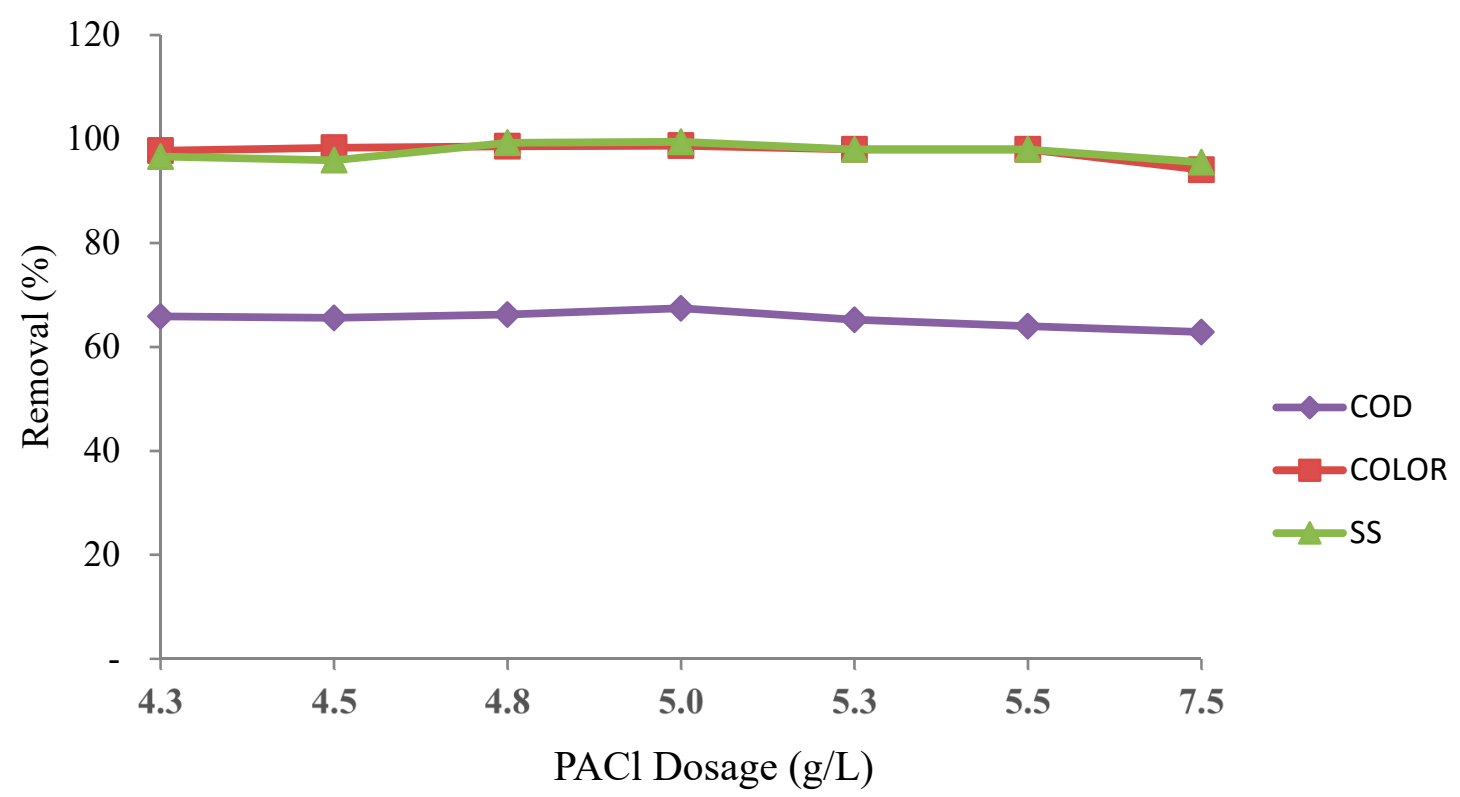

Figure 7. The effect of $\mathrm{PACl}$ major range of dosage on the removal of COD, color and SS at a constant $\mathrm{pH} 6$.

\subsection{Removal Efficiency of SS, Color, and COD Using LSP}

A preliminary coagulant test has been conducted using LSP to determine the optimum $\mathrm{pH}$. From the observation, LSP showed its effectiveness at $\mathrm{pH} 4$ (data not shown). Therefore, the subsequent tests were carried out at $\mathrm{pH} 4$. Different dosages of LSP were used to investigate its effect on the removal of color, SS, and COD at constant $\mathrm{pH} 4$ as shown in Figure 8. Results show that the maximum removal efficiencies of color, SS, and COD were $28.3 \%, 11.2 \%$ and $15.1 \%$, respectively at $2 \mathrm{~g} / \mathrm{L}$ of LSP dosage.

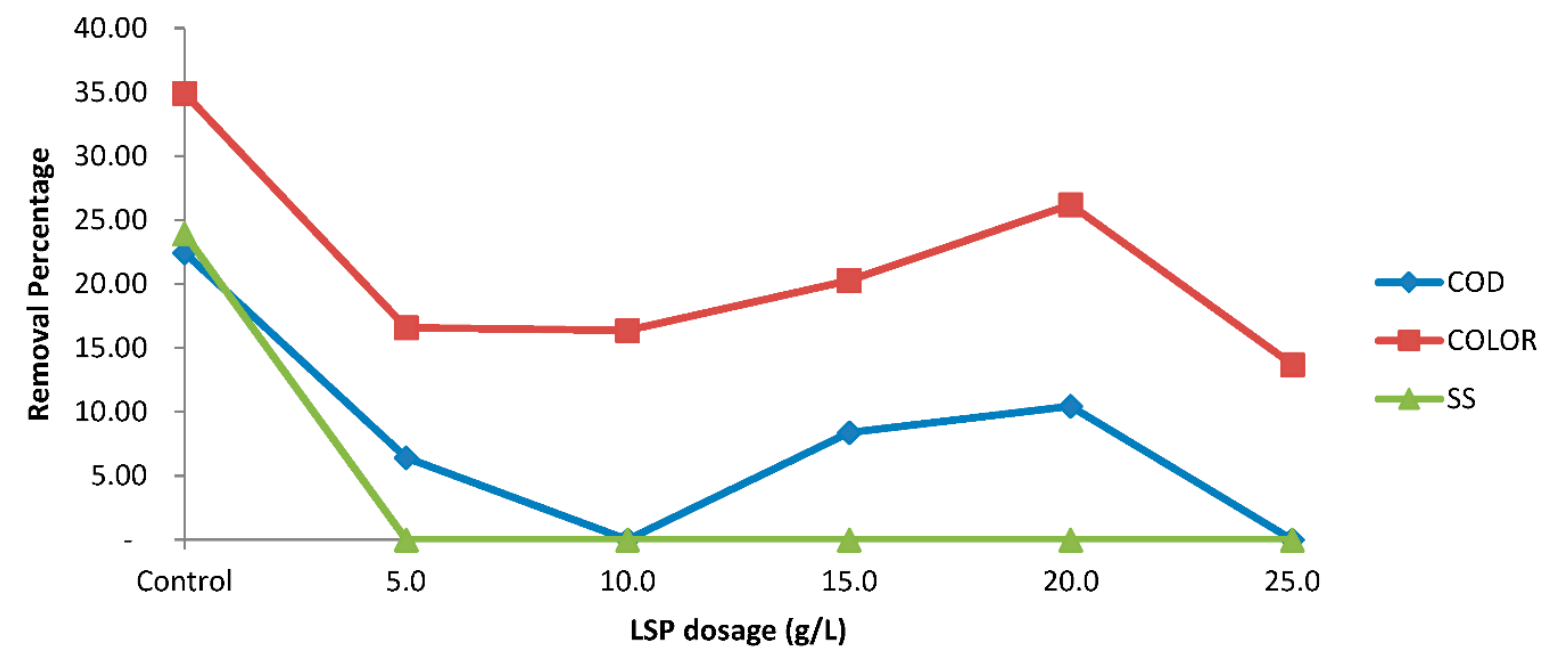

Figure 8. The effect of LSP in major dosages on the removal of color, SS, and COD at a constant pH 4.

Therefore, the optimum dosage of LSP was $2 \mathrm{~g} / \mathrm{L}$. It was found that at a higher concentration of LSP, the removal efficiencies of color, SS and COD was decreasing gradually until $5 \mathrm{~g} / \mathrm{L}$ dosage. Thereafter, the removal efficiencies fluctuated for COD and color and remained at zero for SS. 


\subsection{PACl as the Main Coagulant with LSP as a Coagulant Aid}

Optimum dosage of PACl $(5 \mathrm{~g} / \mathrm{L})$ was added to different dosages of LSP by fixing the same conditions of jar test for the slow and rapid mixing followed by settling for $2 \mathrm{~h}$ at the optimum $\mathrm{pH} 6$ for PACl. LSP dosage as coagulant aid, (0 g/L as a control sample) with 0.5, 1.0, 2.0, 4.0, 6.0, 8.0 and $10.0 \mathrm{~g} / \mathrm{L}$ were used for pollutant removal and for reducing the dosage of primary coagulant.

Figure 9 shows the effect of LSP as a coagulant aid to remove COD, color, and SS at a different concentration of $\mathrm{PACl}$. In the $\mathrm{PACl}$ predetermined test, $5.0 \mathrm{~g} / \mathrm{L}$ was used as optimum dosage and resulted in removal efficiencies of $67.44 \%, 98.73 \%$, and $99.47 \%$ for COD, color, and SS. However, when LSP was used as a coagulant aid, the results were better than the use of only PACl in terms of reducing the dosage of $\mathrm{PACl}$ and increase the removal efficiencies. The performance of COD removal has been improved from $67.44 \%$ to $69.19 \%$ at $2.75 \mathrm{~g} / \mathrm{L}$ of PACl with the combination of $2 \mathrm{~g} / \mathrm{L}$ of LSP as a coagulant aid when compared with $5 \mathrm{~g} / \mathrm{L} \mathrm{PACl}$ alone. In the coagulation test for the optimum dosage, it was found that $\mathrm{PACl}$ alone was able to remove $98 \%$ color at $5.0 \mathrm{~g} / \mathrm{L}$ concentration. From the graph, it shows that as LSP dose increased from 1.0 to $10.0 \mathrm{~g} / \mathrm{L}$; the removal rates of color also almost similar for all LSP dosages. The maximum removal efficiency of color $(98.80 \%)$ was obtained at LSP dosage of $2 \mathrm{~g} / \mathrm{L}$ and $2.75 \mathrm{~g} / \mathrm{L} \mathrm{PACl}$. Furthermore, the highest removal of SS was detected at the same combination of $2 \mathrm{~g} / \mathrm{L} \mathrm{LSP}$ and $2.75 \mathrm{~g} / \mathrm{L} \mathrm{PACl}$ with $99.50 \%$ removal efficiency.

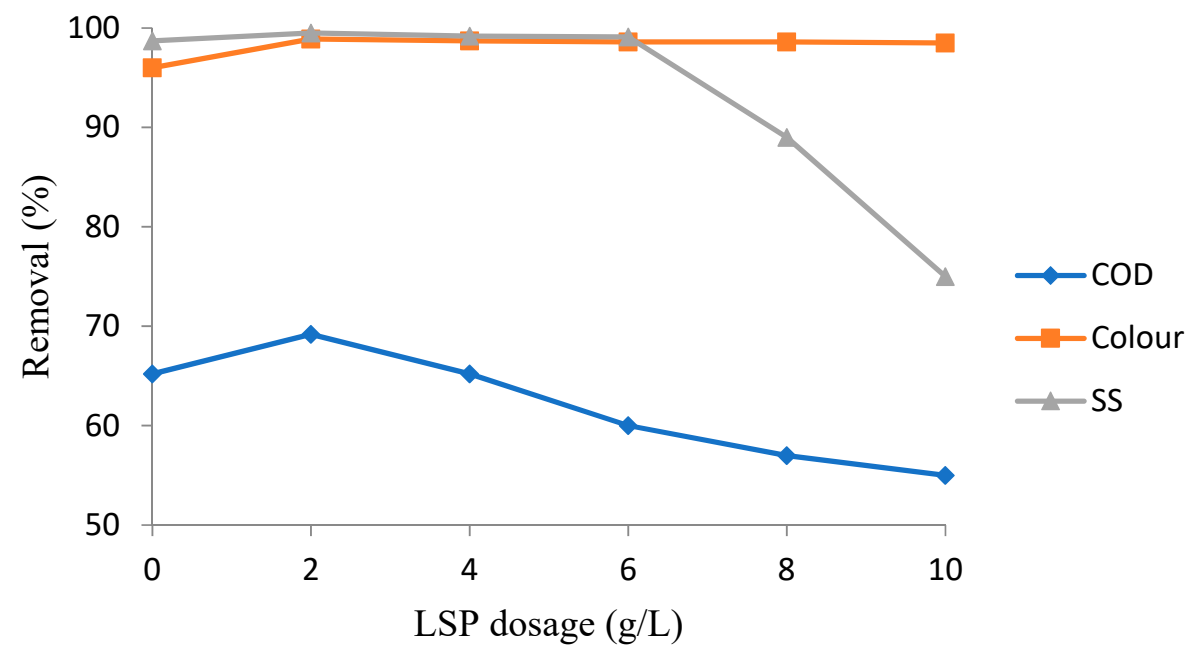

Figure 9. The effect of LSP as coagulant aid on the removal of color, SS, and COD at a constant pH 6 and using $2.75 \mathrm{~g} / \mathrm{L}$ of $\mathrm{PACl}$ dosage.

Figure 10 shows a comparison between the efficiency of using $\mathrm{PACl}$ in landfill leachate treatment alone with two different dosages $(5 \mathrm{~g} / \mathrm{L}$ and $2.75 \mathrm{~g} / \mathrm{L})$ and using a combination of $\mathrm{PACl}$ as a coagulant in conjunction with LSP as a coagulant aid. From the graph, it is clear that the removal efficiency of COD, color, and SS was better when the PACl was used in conjunction with LSP as a coagulant aid. The dose of metal coagulant can be reduced without affecting the removal performance when polyelectrolyte is used as a coagulant aid because polyelectrolyte has higher charge density and molecular weight which act as an important role in coagulation. This is due to the addition of coagulant aid could help to form bigger flocs and produced more particles sediment, thus increasing the sedimentation rate [47]. Formation of flocs became quicker when LSP is used as a coagulant aid. 


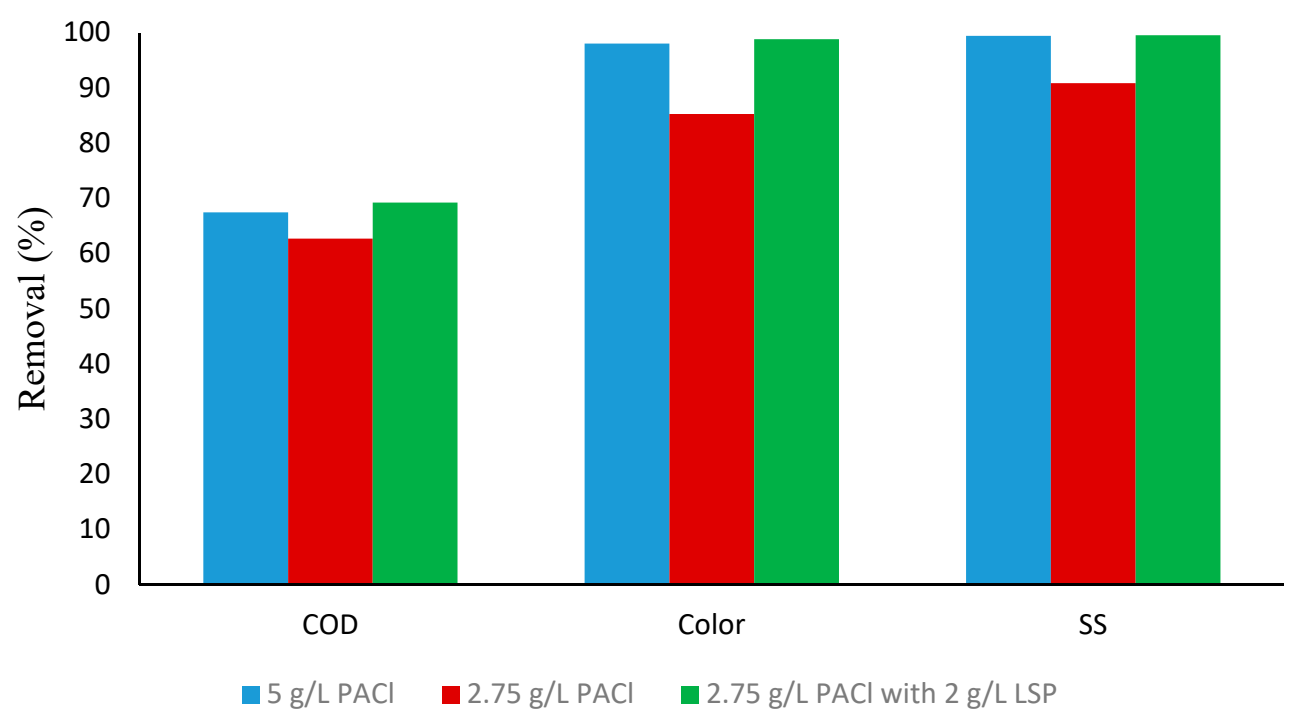

Figure 10. Comparison of using $\mathrm{PACl}$ alone and $\mathrm{PACl}$ in conjunction with LSP as a coagulant aid.

\subsection{Coagulant Cost Estimation}

Generally, the leachate treatment cost depends on factors, such as landfill design, the quantity of leachate, level or degree of treatment needed, and final removal method for residues and effluent. Obtaining data on the cost of leachate treatment is difficult because it requires the cooperation of the company in charge. Therefore, on the basis of the chemicals used, the costs of both coagulants are estimated. Table 2 showed the cost comparisons when the LSP was used as the coagulant aid. From the comparisons, a cost of RM 7800 was found when $5 \mathrm{~g} / \mathrm{L}$ of $\mathrm{PACl}$ was used alone, whereas the use of $2 \mathrm{~g} / \mathrm{L}$ of LSP as coagulant aid only cost RM 4646 , a reduction of approximately $40 \%$ of the cost.

Table 2. Cost estimation for PACl and LSP.

\begin{tabular}{cccccc}
\hline Coagulant & $\begin{array}{c}\text { Price of } \\
\text { Chemical } \\
\text { (RM) }\end{array}$ & $\begin{array}{c}\text { Optimum } \\
\text { Concentration } \\
\text { Used }\end{array}$ & $\begin{array}{c}\text { Amount of Chemical } \\
\text { to Treat } \mathbf{1} \mathbf{~ m}^{\mathbf{3}} \text { of } \\
\text { Leachate/Day }\end{array}$ & $\begin{array}{c}\text { The Cost to Treat } \\
\mathbf{1 ~ m}^{\mathbf{3}} \text { of Leachate } \\
\text { (RM) }\end{array}$ & $\begin{array}{c}\text { Total } \\
\text { (RM) * }\end{array}$ \\
\hline $5000 \mathrm{mg} / \mathrm{L} \mathrm{PACl}$ & $300 / \mathrm{L}$ & $13 \mathrm{~mL} / 500 \mathrm{~mL}$ & $26 \mathrm{~L}$ & 7800 & 7800 \\
$2750 \mathrm{mg} / \mathrm{L} \mathrm{PACl}$ & $300 / \mathrm{L}$ & $7.6 \mathrm{~mL} / 500 \mathrm{~mL}$ & $15.2 \mathrm{~L}$ & 4560 & 4646 \\
$2000 \mathrm{mg} / \mathrm{L} \mathrm{LSP}$ & $4.30 / \mathrm{kg}$ & $10 \mathrm{~g} / 500 \mathrm{~mL}$ & $20 \mathrm{~kg}$ & 86 & \\
\hline
\end{tabular}

${ }^{*} 1 \mathrm{USD}=4 \mathrm{RM}$.

\section{Conclusions}

The application of the coagulation-flocculation process to landfill leachate was examined in this study using longan seed powder (LSP) as a natural coagulant aid. LSP was not effective when used as a main coagulant. Compared to when $\mathrm{PACl}$ was used alone, a slight improvement of COD, color, and SS removal efficiencies were obtained when PACl was used as a main coagulant and LSP as a coagulant aid. The maximum removal efficiencies of COD, color, and SS were $69.19 \%, 98.80 \%$, and $99.50 \%$, respectively. In addition, using of LSP as coagulant aid was able to reduce the PACl dosage from $5 \mathrm{~g} / \mathrm{L}$ when used alone to $2.75 \mathrm{~g} / \mathrm{L}$ when used with conjunction of LSP. A cost estimation for using LSP as a coagulant aid showed a reduction in the cost of using PACl alone of approximately $40 \%$ from the cost of PACl. Overall, this study confirmed that LSP is an effective material to be used as a natural coagulant aid for landfill leachate treatment.

Author Contributions: H.A.A. conceived and designed the experiments, N.A.R. performed the experiments, M.Y.D.A. wrote and revised the paper, S.F.R. and F.M.O. conducted the data analysis, and Y.-T.H revised and proofread the paper. 
Funding: This work was funded by Universiti Sains Malaysia under iconic grant scheme [Grant No. 1001/CKT/870023] for research associated with the Solid Waste Management Cluster, Engineering Campus, Universiti Sains Malaysia.

Conflicts of Interest: The authors declare no conflicts of interest.

\section{References}

1. Zamri, M.F.M.A.; Kamaruddin, M.A.; Yusoff, M.S.; Aziz, H.A.; Foo, K.Y. Semi-aerobic stabilized landfill leachate treatment by ion exchange resin: Isotherm and kinetic study. Appl. Water Sci. 2017, 7, 581-590. [CrossRef]

2. Aziz, H.A.; Alias, S.; Adlan, M.N.; Asaari, A.; Zahari, M.S. Colour removal from landfill leachate by coagulation and flocculation processes. Bioresour. Technol. 2007, 98, 218-220. [CrossRef] [PubMed]

3. Fang, C.; Chu, Y.; Jiang, L.; Wang, H.; Long, Y.; Shen, D. Removal of phthalic acid diesters through a municipal solid waste landfill leachate treatment process. J. Mater. Cycles Waste Manag. 2018, 20, 585-591. [CrossRef]

4. Aziz, H.A.; Yusoff, M.S.; Adlan, M.N.; Adnan, N.H.; Alias, S. Physico-chemical removal of iron from semi-aerobic landfill leachate by limestone filter. Waste Manag. 2004, 24, 353-358. [CrossRef] [PubMed]

5. Wang, Z.-P.; Zhang, Z.; Lin, Y.-J.; Deng, N.-S.; Tao, T.; Zhuo, K. Landfill leachate treatment by a coagulation-photooxidation process. J. Hazard. Mater. 2002, 95, 153-159. [CrossRef]

6. Wang, Y.; Gong, B.; Lin, Z.; Wang, J.; Zhang, J.; Zhou, J. Robustness and microbial consortia succession of simultaneous partial nitrification, ANAMMOX and denitrification (SNAD) process for mature landfill leachate treatment under low temperature. Biochem. Eng. J. 2018, 132, 112-121. [CrossRef]

7. Kulikowska, D.; Klimiuk, E. The effect of landfill age on municipal leachate composition. Bioresour. Technol. 2008, 99, 5981-5985. [CrossRef] [PubMed]

8. Umar, M.; Aziz, H.A.; Yusoff, M.S. Trends in the use of Fenton, electro-Fenton and photo-Fenton for the treatment of landfill leachate. Waste Manag. 2010, 30, 2113-2121. [CrossRef] [PubMed]

9. Agamuthu, P.; Fauziah, S. Solid waste landfilling: Environmental factors and health. In Proceedings of the EU-Asia Solid Waste Management Conference, Perak, Malaysia, 28-29 October 2008.

10. Dia, O.; Drogui, P.; Buelna, G.; Dubé, R. Hybrid process, electrocoagulation-biofiltration for landfill leachate treatment. Waste Manag. 2018, 75, 391-399. [CrossRef] [PubMed]

11. Uygur, A.; Karg1, F. Biological nutrient removal from pre-treated landfill leachate in a sequencing batch reactor. J. Environ. Manag. 2004, 71, 9-14. [CrossRef] [PubMed]

12. Ahn, D.-H.; Chung, Y.-C.; Chang, W.-S. Use of coagulant and zeolite to enhance the biological treatment efficiency of high ammonia leachate. J. Environ. Sci. Health Part A 2002, 37, 163-173. [CrossRef]

13. Aziz, H.A.; Daud, Z.; Adlan, M.N.; Hung, Y.-T. The use of polyaluminium chloride for removing colour, COD and ammonia from semi-aerobic leachate. Int. J. Environ. Eng. 2009, 1, 20-35. [CrossRef]

14. Bashir, M.J.K.; Aziz, H.A.; Yusoff, M.S.; Huqe, A.; Mohajeri, S. Effects of ion exchange resins in different mobile ion forms on semi-aerobic landfill leachate treatment. Water Sci. Technol. 2010, 61, 641-649. [CrossRef] [PubMed]

15. Al-Hamadani, Y.A.; Yusoff, M.S.; Umar, M.; Bashir, M.J.; Adlan, M.N. Application of psyllium husk as coagulant and coagulant aid in semi-aerobic landfill leachate treatment. J. Hazard. Mater. 2011, 190, 582-587. [CrossRef] [PubMed]

16. Postacchini, L.; Ciarapica, F.E.; Bevilacqua, M. Environmental assessment of a landfill leachate treatment plant: Impacts and research for more sustainable chemical alternatives. J. Clean. Prod. 2018, 183, 1021-1033. [CrossRef]

17. Bashir, M.J.K.; Aziz, H.A.; Yusoff, M.S. New sequential treatment for mature landfill leachate by cationic/anionic and anionic/cationic processes: Optimization and comparative study. J. Hazard. Mater. 2011, 186, 92-102. [CrossRef] [PubMed]

18. Onay, T.T.; Pohland, F.G. In situ nitrogen management in controlled bioreactor landfills. Water Res. 1998, 32, 1383-1392. [CrossRef]

19. Chiang, L.-C.; Chang, J.-E.; Chung, C.-T. Electrochemical oxidation combined with physical-chemical pretreatment processes for the treatment of refractory landfill leachate. Environ. Eng. Sci. 2001, 18, 369-379. [CrossRef] 
20. Ishak, A.R.; Hamid, F.S.; Mohamad, S.; Tay, K.S. Stabilized landfill leachate treatment by coagulation-flocculation coupled with UV-based sulfate radical oxidation process. Waste Manag. 2018, 76, 575-581. [CrossRef] [PubMed]

21. Duan, J.; Gregory, J. Coagulation by hydrolysing metal salts. Adv. Colloid Interface Sci. 2003, 100, 475-502. [CrossRef]

22. Kurniawan, T.A.; Lo, W.-H.; Chan, G.Y. Physico-chemical treatments for removal of recalcitrant contaminants from landfill leachate. J. Hazard. Mater. 2006, 129, 80-100. [CrossRef] [PubMed]

23. Amokrane, A.; Comel, C.; Veron, J. Landfill leachates pretreatment by coagulation-flocculation. Water Res. 1997, 31, 2775-2782. [CrossRef]

24. Luo, K.; Pang, Y.; Li, X.; Chen, F.; Liao, X.; Lei, M.; Song, Y. Landfill leachate treatment by coagulation/flocculation combined with microelectrolysis-Fenton processes. Environ. Technol. 2018. [CrossRef] [PubMed]

25. Kaszuba, M.; Corbett, J.; Watson, F.M.; Jones, A. High-concentration zeta potential measurements using light-scattering techniques. Philos. Trans. R. Soc. Lond. A Math. Phys. Eng. Sci. 2010, 368, 4439-4451. [CrossRef] [PubMed]

26. Lee, M.R. Treatment of Landfill Leachate in Coagulation-Flocculation Method by Using Micro Zeolite and Micro Sand. Ph.D. Thesis, Faculty of Civil Engineering, Universiti Tun Hussein Onn Malaysia, Parit Raja, Malaysia, 2013.

27. Fosso-Kankeu, E.; Waanders, F.; Mulaba-Bafubiandi, A.; Mishra, A. Flocculation performances of polymers and nanomaterials for the treatment of industrial wastewaters. Smart Mater. Waste Water Appl. 2016, 7, 213-235.

28. Jadhav, M.V.; Mahajani, Y. A comparative study of natural coagulants in flocculation of local clay suspensions of varied turbidities. Int. J. Civ. Environ. Eng. 2013, 35, 26-39.

29. Santos, T.R.; Silva, M.F.; Nishi, L.; Vieira, A.M.; Klein, M.R.; Andrade, M.B.; Vieira, M.F.; Bergamasco, R. Development of a magnetic coagulant based on Moringa oleifera seed extract for water treatment. Environ. Sci. Pollut. Res. 2016, 23, 7692-7700. [CrossRef] [PubMed]

30. Meraz, K.A.S.; Vargas, S.M.P.; Maldonado, J.T.L.; Bravo, J.M.C.; Guzman, M.T.O.; Maldonado, E.A.L. Eco-friendly innovation for nejayote coagulation-flocculation process using chitosan: Evaluation through zeta potential measurements. Chem. Eng. J. 2016, 284, 536-542. [CrossRef]

31. Zheng, G.; Xu, L.; Wu, P.; Xie, H.; Jiang, Y.; Chen, F.; Wei, X. Polyphenols from longan seeds and their radical-scavenging activity. Food Chem. 2009, 116, 433-436. [CrossRef]

32. Soong, Y.Y.; Barlow, P.J. Isolation and structure elucidation of phenolic compounds from longan (Dimocarpus longan Lour.) seed by high-performance liquid chromatography-electrospray ionization mass spectrometry. J. Chromatogr. A 2005, 1085, 270-277. [CrossRef] [PubMed]

33. Rangkadilok, N.; Sitthimonchai, S.; Worasuttayangkurn, L.; Mahidol, C.; Ruchirawat, M.; Satayavivad, J. Evaluation of free radical scavenging and antityrosinase activities of standardized longan fruit extract. Food Chem. Toxicol. 2007, 45, 328-336. [CrossRef] [PubMed]

34. Zaidi, S.; Jain, P.; Saleem, S.; Rao, K. Extraction and Purification of Total Phenolic Content from seeds of Dimocarpus longan fruit. Res. Rev. J. Pharm. 2018, 4, 19-21.

35. Katayon, S.; Noor, M.M.M.; Asma, M.; Ghani, L.A.; Thamer, A.; Azni, I.; Ahmad, J.; Khor, B.; Suleyman, A. Effects of storage conditions of Moringa oleifera seeds on its performance in coagulation. Bioresour. Technol. 2006, 97, 1455-1460. [CrossRef] [PubMed]

36. Zawawi, M.H.; Abustan, I. Detection of groundwater aquifer using resistivity imaging profiling at Beriah Landfill Site, Perak, Malaysia. Adv. Mater. Res. 2011, 250-253, 1852-1855. [CrossRef]

37. APAH. Standard Methods for the Examination of Water and Waste Water, 21st ed.; American Public Health Association: Washington, DC, USA, 2005.

38. Makhtar, S.M.Z.; Ab Wahab, M.; Selimin, M.T.; Mohamed, N.C. Landfill Leachate Treatment by a Coagulation-Photocatalytic Process. In Proceedings of the 2011 International Conference on Environment and Industrial Innovation (ICEII 2011), Kuala Lumpur, Malaysia, 4-5 June 2011.

39. Li, L.C.; Tiau, Y. Zeta Potential; Mercel Dekker: New York, NY, USA, 1997.

40. Salem, Z.; Hamouri, K.; Djemaa, R.; Allia, K. Evaluation of landfill leachate pollution and treatment. Desalination 2008, 220, 108-114. [CrossRef] 
41. Bashir, M.J.K.; Aziz, H.A.; Yusoff, M.S.; Adlan, M.N. Application of response surface methodology (RSM) for optimization of ammoniacal nitrogen removal from semi-aerobic landfill leachate using ion exchange resin. Desalination 2010, 254, 154-161. [CrossRef]

42. Awang, N.A.; Aziz, H.A. Hibiscus rosa-sinensis leaf extract as coagulant aid in leachate treatment. Appl. Water Sci. 2012, 2, 293-298. [CrossRef]

43. Jamali, H.A.; Mahvi, A.H.; Nabizadeh, R.; Vaezi, F.; Omrani, G.A. Combination of coagulation-flocculation and ozonation processes for treatment of partially stabilized landfill leachate of Tehran. World Appl. Sci. J. 2009, 5, 9-15.

44. Baghvand, A.; Zand, A.D.; Mehrdadi, N.; Karbassi, A. Optimizing coagulation process for low to high turbidity waters using aluminum and iron salts. Am. J. Environ. Sci. 2010, 6, 442-448. [CrossRef]

45. Rui, L.M.; Daud, Z.; Latif, A.A.A. Treatment of Leachate by coagulation-flocculation using different coagulants and polymer: A review. Int. J. Adv. Sci. Eng. Inf. Technol. 2012, 2, 114-117. [CrossRef]

46. Sugimoto, T.; Cao, T.; Szilagyi, I.; Borkovec, M.; Trefalt, G. Aggregation and Charging of Sulfate and Amidine Latex Particles in the Presence of Oxyanions. J. Colloid Interface Sci. 2018, 524, 456-464. [CrossRef] [PubMed]

47. Abood, A.R.; Bao, J.; Abudi, Z.N.; Zheng, D.; Gao, C. Pretreatment of nonbiodegradable landfill leachate by air stripping coupled with agitation as ammonia stripping and coagulation-flocculation processes. Clean Technol. Environ. Policy 2013, 15, 1069-1076. [CrossRef]

(C) 2018 by the authors. Licensee MDPI, Basel, Switzerland. This article is an open access article distributed under the terms and conditions of the Creative Commons Attribution (CC BY) license (http:/ / creativecommons.org/licenses/by/4.0/). 